\title{
Stability in community-acquired pneumonia: one step forward with markers?
}

\author{
R Menéndez, ${ }^{1}$ R Martinez, ${ }^{1}$ S Reyes, ${ }^{1} \mathrm{~J}$ Mensa, ${ }^{2}$ E Polverino, ${ }^{3}$ X Filella, ${ }^{4}$ C Esquinas, ${ }^{3}$ \\ A Martinez, ${ }^{1}$ P Ramirez, ${ }^{5}$ A Torres ${ }^{3}$
}

${ }^{1}$ Servicio de Neumología.

Universitary Hospital La Fe, Ciber de enfermedades respiratorias (CIBERES),Valencia, Spain; ${ }^{2}$ Servicio de Infecciosas, Hospital Clinic, IDIBAPS, Barcelona, Spain; ${ }^{3}$ Servicio de Neumología, Hospital Clinic, IDIBAPS Ciber de enfermedades respiratorias (CIBERES)

Barcelona, Spain; ${ }^{4}$ Servicio de Bioquímica, Hospital Clinic, IDIBAPS, Barcelona, Spain; ${ }^{5}$ Unidad de Cuidados Intensivos, Universitary Hospital La Fe, Valencia, Spain

Correspondence to: Dr R Menéndez, Servicio de Neumología, Hospital Universitario La Fe, Avda de Campanar 21, 46009 Valencia Spain; rmenend@separ.es

Received 26 April 2009 Accepted 13 August 2009

\section{ABSTRACT}

Background: Biological markers as an expression of systemic inflammation have been recognised as useful for evaluating the host response in community-acquired pneumonia (CAP). The objective of this study was to evaluate whether the biological markers procalcitonin (PCT) and C-reactive protein (CRP) might reflect stability after $72 \mathrm{~h}$ of treatment and the absence of subsequent severe complications.

Methods: A prospective cohort study was performed in 394 hospitalised patients with CAP. Clinical stability was evaluated using modified Halm's criteria: temperature $\leqslant 37.2^{\circ} \mathrm{C}$; heart rate $\leqslant 100$ beats/min; respiratory rate $\leqslant 24$ breaths/min; systolic blood pressure $\geqslant 90 \mathrm{~mm} \mathrm{Hg}$; oxygen saturation $\geqslant 90 \%$; or arterial oxygen tension $\geqslant 60 \mathrm{~mm} \mathrm{Hg}$. PCT and CRP levels were measured on day 1 and after $72 \mathrm{~h}$. Severe complications were defined as mechanical ventilation, shock and/or intensive care unit (ICU) admission, or death after $72 \mathrm{~h}$ of treatment.

Results: 220 patients achieved clinical stability at $72 \mathrm{~h}$ and had significantly lower levels of CRP (4.2 vs $7 \mathrm{mg} / \mathrm{dl}$ ) and of PCT (0.33 vs $0.48 \mathrm{ng} / \mathrm{ml}$ ). Regression logistic analyses were performed to calculate several areas under the ROC curve (AUC) to predict severe complications. The AUC for clinical stability was $0.77,0.84$ when CRP was added $(p=0.059)$ and 0.77 when PCT was added $(p=0.45)$. When clinical stability was achieved within $72 \mathrm{~h}$ and marker levels were below the cut-off points $(0.25 \mathrm{ng} / \mathrm{ml}$ for PCT and $3 \mathrm{mg} / \mathrm{dl}$ for CRP), no severe complications occurred.

Conclusions: Low levels of CRP and PCT at $72 \mathrm{~h}$ in addition to clinical criteria might improve the prediction of absence of severe complications.

Prognostic scales provide key information on predicting mortality, but this information is insufficient for assessing the response to antibiotic treatment and clinical stability. ${ }^{1}$ The concept of clinical stability is very important for the clinician since it allows decision-making concerning hospital discharge and treatment length. The publication of stability clinical criteria by Halm et a ${ }^{2}$ provided a fundamental basis to define this concept which has already been included in guidelines. ${ }^{3}$ Nevertheless, clinical criteria are sometimes difficult to evaluate in elderly patients with low clinical expression, multiple associated diseases or with chronic respiratory insufficiency. Because of this, it would be of great value to have objective and easily measurable data to indicate "biological stability".

Markers such as C-reactive protein (CRP) and procalcitonin (PCT) have been used to quantify severity, systemic inflammation and prognosis. ${ }^{4-9}$ It has been observed that an increase in markers and cytokines within $72 \mathrm{~h}$ of admission to hospital is associated with treatment failure and a poor outcome. ${ }^{1}$ Furthermore, a reduction in these levels is associated with a good response. ${ }^{189}$ An interesting perspective would be to evaluate the usefulness of markers in providing information on the resolution of the degree of inflammation after antibiotic treatment. It is known that $72 \mathrm{~h}$ after adequate treatment the concentration of microorganisms is dramatically reduced ${ }^{10}$ and clinical stability is then reached. ${ }^{211}$ Our hypothesis is that, when clinical stability is reached, the reduction in the markers is larger due to the fact that systemic inflammation is at a low safe level for the patient. If this can be demonstrated, levels of systemic markers could be used either on their own or jointly with clinical criteria of stability to decide safely whether there is a subsequent risk for the patient.

The objectives of this study are (1) to investigate if there is a correlation between clinical stability and levels of biological markers; (2) to evaluate whether biomarkers and/or assessment of clinical stability criteria can predict the absence of severe complications; and (3) to find or define the best cut-off points for PCT and CRP which enable the absence of severe complications or a poor prognosis after $72 \mathrm{~h}$ of antibiotic treatment to be identified.

\section{METHODS}

\section{Patients}

A prospective longitudinal study was conducted in patients with CAP consecutively admitted to two tertiary care teaching hospitals from October 2003 to June 2004. Inclusion criteria were a new radiographic infiltrate compatible with the presence of acute pneumonia and at least two signs or symptoms of CAP (eg, temperature $>38^{\circ} \mathrm{C}$, productive cough, chest pain, shortness of breath, crackles on auscultation). Exclusion criteria were admission within the previous 15 days, nursing home patients, immunosuppressive treatment and/or steroids (>15 mg/day), leucocyte count $<1000 / \mathrm{mm}^{3}$ or neutrophil count $<500 / \mathrm{mm}^{3}$ (except if attributable to CAP).

\section{Data collection}

Data on age, gender, smoking and alcohol habits (>80 g/day), prior influenza vaccination with that year's trivalent inactivated influenza vaccine before developing pneumonia, comorbid diseases such as chronic obstructive pulmonary disease, and cardiac, liver, renal or central nervous system disorders were collected. Recorded clinical signs and 
symptoms were: cough, expectoration, pleuritic chest pain, dyspnoea, acute confusion, temperature, respiratory and heart rates, systolic and diastolic blood pressure and the presence of rales. The following analytical data were recorded: leucocyte count, sodium, potassium, serum creatinine, ALT/AST and arterial blood gas analysis. On admission, Fine risk classes ${ }^{12}$ and CURB-65 were also recorded. ${ }^{13}$ Initial empirical antimicrobial treatment was recorded and classified as follows: $\beta$-lactam (ceftriaxone/cefotaxime or co-amoxi-clavulanate) with a macrolide (clarithromycin or azithromycin), fluoroquinolone (levofloxacin), $\beta$-lactam with quinolone, $\beta$-lactam as monotherapy and other regimens. Surviving patients underwent radiological and serological follow-up after 30 days.

\section{Definitions}

Clinical stability was defined following a slight modification of Halm's criteria ${ }^{211}$ as the condition when the following threshold values were achieved for all parameters: temperature $\leqslant 37.2^{\circ} \mathrm{C}$, heart rate $\leqslant 100$ beats/min, respiratory rate $\leqslant 24$ breaths/min, systolic blood pressure $\geqslant 90 \mathrm{~mm} \mathrm{Hg}$ and oxygen saturation $\geqslant 90 \%$ or arterial oxygen tension $\geqslant 60 \mathrm{~mm} \mathrm{Hg}$ when the patient was not receiving supplemental oxygen. In patients on home oxygen therapy, stability was considered to be achieved when their oxygen needs were the same as those before admission.

The primary outcome-severe complications after $72 \mathrm{~h}$ of treatment-was defined as death after $72 \mathrm{~h}$ of treatment and within 30 days of admission; shock or need for mechanical ventilation (invasive or non-invasive); or admission to the ICU after $72 \mathrm{~h}$ of treatment.

\section{Determination of cytokines, PCT and CRP}

Blood samples were drawn on the first day and centrifuged, coded and frozen at $-80^{\circ} \mathrm{C}$ until subsequent analyses. Determination of interleukin (IL)-6, IL-8, IL-10 and tumour necrosis factor $\alpha(\mathrm{TNF} \alpha)$ was performed with a commercial enzyme immunoassay technique (Biosource, Nivelles, Belgium). Limits of detection were $3 \mathrm{pg} / \mathrm{ml}$ for TNF $\alpha, 2 \mathrm{pg} / \mathrm{ml}$ for IL-6, $0.7 \mathrm{pg} / \mathrm{ml}$ for IL-8 and $1 \mathrm{pg} / \mathrm{ml}$ for IL-10. An immunoluminometric technique was used to measure PCT (Liaison Bhams PCT, DiaSorin, Saluggia, Italy) with a detection limit of $0.3 \mathrm{ng} / \mathrm{ml}$. CRP was measured with an immunoturbidimetric method using a commercially available test (Bayer Diagnostics) with an Advia 2400 (detection limit $1.5 \mathrm{mg} / \mathrm{dl}$ ).

\section{Statistical analysis}

Statistical analysis was performed using SPSS Version 15.0 software. The $\chi^{2}$ test was used for qualitative variables and the Student $t$ test or Mann-Whitney $U$ test for quantitative variables. Correlation was analysed using Spearman rho correlation analysis.

Several multivariate logistic regression analyses were performed to predict the absence of severe complications after day

Table 1 Characteristics, comorbidity and initial severity, and clinical stability

\begin{tabular}{|c|c|c|c|}
\hline \multirow[b]{3}{*}{ Characteristics } & \multicolumn{2}{|l|}{ Stability } & \multirow[b]{3}{*}{ p Value } \\
\hline & $\leqslant 3$ days & $>3$ days & \\
\hline & $n=220(55.8 \%)$ & $n=174(44.2 \%)$ & \\
\hline Mean (SD) age (years) & $65(17)$ & $67(18)$ & 0.2 \\
\hline $\mathrm{F} / \mathrm{M}(\%)$ & $76 / 144(34.5 / 65.5)$ & $72 / 102(41.4 / 58.6)$ & 0.1 \\
\hline Current smokers, n (\%) & $46(20.9)$ & $44(25.3)$ & 0.3 \\
\hline Excessive alcohol consumption, $\mathrm{n}(\%)$ & $25(11.4)$ & $21(12.1)$ & 0.8 \\
\hline Prior influenza vaccination, $\mathrm{n}(\%)$ & $98(44.5)$ & $66(37.9)$ & 0.2 \\
\hline \multicolumn{4}{|l|}{ Coexisting illnesses, n (\%) } \\
\hline Cardiac insufficiency & $40(18.2)$ & $25(14.4)$ & 0.3 \\
\hline Renal insufficiency & $12(5.5)$ & $8(4.6)$ & 0.7 \\
\hline Diabetes & $49(22.3)$ & $29(16.7)$ & 0.1 \\
\hline Liver disease & $5(2.3)$ & $6(3.4)$ & 0.4 \\
\hline COPD & $39(17.7)$ & $31(17.8)$ & 0.9 \\
\hline Neurological disease & $38(17.3)$ & $31(17.8)$ & 0.8 \\
\hline \multicolumn{4}{|l|}{ PSI, n (\%) } \\
\hline I & $32(14.5)$ & $15(8.6)$ & 0.07 \\
\hline ॥ & $42(19.1)$ & $28(16.1)$ & 0.4 \\
\hline III & $49(22.3)$ & $39(22.4)$ & 0.9 \\
\hline IV & $79(35.9)$ & $63(36.2)$ & 0.9 \\
\hline V & $18(8.2)$ & $29(16.7)$ & 0.01 \\
\hline \multicolumn{4}{|l|}{ CURB-65, n (\%) } \\
\hline 0 & $41(18.6)$ & $22(12.6)$ & 0.1 \\
\hline 1 & $84(38.2)$ & $48(27.6)$ & 0.1 \\
\hline 2 & $55(25.0)$ & $54(31.0)$ & 0.1 \\
\hline 3 & $32(14.5)$ & $34(19.4)$ & 0.1 \\
\hline 4 & $8(3.6)$ & $14(8.0)$ & 0.06 \\
\hline 5 & 0 & $2(1.1)$ & 0.1 \\
\hline \multicolumn{4}{|l|}{ Antibiotic therapy, n (\%) } \\
\hline$\beta$-lactam/macrolide combination & $127(57.7)$ & $103(59.2)$ & 0.7 \\
\hline Fluoroquinolone & $64(29.1)$ & $30(17.2)$ & 0.006 \\
\hline$\beta$-lactam/quinolone combination & $8(3.6)$ & $18(10.3)$ & 0.008 \\
\hline$\beta$-lactam monotherapy & $12(5.5)$ & $9(5.2)$ & 0.9 \\
\hline Other* & $9(4.1)$ & $14(8.0)$ & 0.09 \\
\hline
\end{tabular}

F/M, female/male; COPD, chronic obstructive pulmonary disease; PSI, pneumonia severity index (Fine risk class)

*Other antibiotic regimens. 
Table 2 Results of cytokines and markers on days 1 and 3

\begin{tabular}{|c|c|c|c|}
\hline \multirow[b]{3}{*}{ Cytokines } & \multicolumn{2}{|l|}{ Clinical stability } & \multirow[b]{3}{*}{ p Value } \\
\hline & $\leqslant 3$ days & $>3$ days & \\
\hline & Median $\left(\mathbf{P}_{25}-\mathbf{P}_{75}\right)$ & Median $\left(\mathbf{P}_{25}-\mathbf{P}_{75}\right)$ & \\
\hline \multicolumn{4}{|l|}{ Day 1} \\
\hline CRP (mg/dl) & $12.2(5.9-21.6)$ & $17.3(10.4-28.5)$ & 0.0001 \\
\hline РCT (ng/ml) & $0.43(0.24-1.72)$ & $0.93(0.34-4.31)$ & 0.0003 \\
\hline $\mathrm{TNF} \alpha(\mathrm{pg} / \mathrm{ml})$ & $27(16-45)$ & $31(19-48)$ & 0.1 \\
\hline IL-1 (pg/ml) & $21(7-36)$ & $18(0-30)$ & 0.08 \\
\hline IL-6 (pg/ml) & $63(25-150)$ & $101(47-267)$ & 0.0003 \\
\hline IL-10 (pg/ml) & $5(0-17)$ & $10(3-19)$ & 0.004 \\
\hline IL-8 (pg/ml) & $6(2-14)$ & $6(2-15)$ & 0.9 \\
\hline \multicolumn{4}{|l|}{ Day 3} \\
\hline CRP (mg/dl) & $4.2(1.8-9.8)$ & $7.0(2.8-14.2)$ & 0.0003 \\
\hline РCT (ng/ml) & $0.33(0.17-0.60)$ & $0.48(0.25-1.09)$ & 0.003 \\
\hline $\mathrm{TNF} \alpha(\mathrm{pg} / \mathrm{ml})$ & $26(14-43)$ & $28(14-47)$ & 0.4 \\
\hline IL-1 (pg/ml) & 13 (4-28) & $14(3-25)$ & 0.8 \\
\hline IL-6 (pg/ml) & $24(7-75)$ & $49(16-111)$ & 0.003 \\
\hline IL-10 (pg/ml) & $4(0-14)$ & $6(2-19)$ & 0.03 \\
\hline IL-8 (pg/ml) & $7(2-14)$ & $6(2-15)$ & 0.9 \\
\hline
\end{tabular}

CRP, C-reactive protein; IL, interleukin; PCT, procalcitonin; TNF $\alpha$, tumour necrosis factor $\alpha$.

3 (dependent variable). Independent variables were clinical stability within the first $72 \mathrm{~h}$ of treatment, levels of CRP on day 3 and levels of PCT on day 3.

In order to calculate the predictive value of markers (CRP and PCT) together with clinical criteria of stability, the area under the ROC curve (AUC) was calculated from the multivariate logistic regression analyses performed with several combinations. For each regression logistic model the AUC was calculated for absence of severe complications. Statistical comparison of AUCs was conducted according to the Hanley and McNeil method: ${ }^{14} \mathrm{p}$ values $<0.05$ were considered significant. For resulting models, sensitivity, specificity and positive and negative predictive values were calculated. Hosmer and Lemeshow goodness-of-fit test was performed for each model..$^{15}$

\section{RESULTS}

\section{Patient population}

During the study period 394 patients with a mean (SD) age of 66.5 (17.2) years were included. Clinical stability after $72 \mathrm{~h}$ of antibiotics was reached by 220 patients (55.8\%). Main demographic characteristics, comorbidity and initial severity in the two groups with clinical stability at $72 \mathrm{~h}$ or later are shown in table 1. Prescribed initial antimicrobial treatments were: 250 (58.3\%) $\beta$ lactam (ceftriaxone/cefotaxime or co-amoxi-clavulanate) plus macrolide (clarithromycin or azithromycin), 99 (23.1\%) fluoroquinolone (levofloxacin), 29 (6.8\%) $\beta$-lactam plus quinolone, 24 (5.6\%) $\beta$-lactam as monotherapy and $27(6.3 \%)$ other regimens. The differences between groups are shown in table 1.

Twenty-four patients (5.6\%) died during hospitalisation. Mortality within 30 days was $6.8 \%$ (29 patients). After $72 \mathrm{~h}$ of treatment, 31 patients (7.2\%) developed severe complications: 4 were admitted to the ICU, 8 required mechanical ventilation, 10 suffered from shock and 23 died.

Most frequently found microorganisms were: Streptococcus pneumoniae $(\mathrm{n}=79,20 \%)$, Legionella pneumophila $(\mathrm{n}=17,4.3 \%)$, Staphylococcus aureus $(\mathrm{n}=10,2.5 \%)$, Haemophilus influenzae $(\mathrm{n}=11,2.8 \%), \quad$ Pseudomonas aeruginosa $(\mathrm{n}=10,2.5 \%)$, Escherichia coli $(\mathrm{n}=5,1.3 \%)$, Mycoplasma pneumoniae $(\mathrm{n}=5$, $1.3 \%$ ) and 27 other microorganisms. Mixed aetiology was found in 24 patients; 14 had $S$ pneumoniae together with other microorganisms.

\section{Clinical stability and markers \\ Univariate analyses}

The results of markers CRP and PCT according to clinical stability or not are shown in table 2.

Median levels of CRP, PCT, IL-6 and IL-10 were significantly higher in patients who did not reach clinical stability at day 3 (fig 1). Cut-off points of markers to predict the absence of severe complications were selected with the highest specificity and positive predictive value in order not to underestimate any severe complication. After day 3, 5/103 patients with PCT levels $<0.25 \mathrm{ng} / \mathrm{ml}$ developed severe complications compared with $22 / 213$ patients with higher PCT levels $(p<0.05)$, and $3 / 105$ patients with CRP levels $<3 \mathrm{mg} / \mathrm{dl}$ developed severe complications compared with 24/214 patients with higher CRP levels $(\mathrm{p}<0.05)$.

Fifteen patients had CRP levels $<3 \mathrm{mg} / \mathrm{dl}$ and PCT levels $<0.25 \mathrm{ng} / \mathrm{ml}$ but did not achieve clinical stability by clinical criteria, and two patients (13.3\%) had subsequent severe complications (one death and one severe respiratory insufficiency with non-invasive mechanical ventilation).

One hundred and thirty-five patients achieved clinical stability on day 3 , but PCT and CRP levels remained high; complications occurred in three patients $(2.2 \%)$ (one septic shock and two died).

When clinical stability was also included in the prediction, the following results were obtained: clinical stability reached and PCT $<0.25 \mathrm{ng} / \mathrm{ml}: 0 / 28$ patients developed severe complications versus $28 / 291$ who did not achieve clinical stability and had higher PCT levels $(p<0.015)$. Similar findings were reported for CRP levels $\leqslant 3 \mathrm{mg} / \mathrm{dl}$ and clinical stability on day $3: 0 / 30$ developed severe complications vs 30/293 patients without stability and higher CRP levels $(p<0.012)$. The diagnostic value for identifying the absence of severe complications is shown in table 3 . When both markers are added to the clinical stability criteria, the predictive value did not increase.

\section{Multivariate analyses}

Three logistic regression analyses were performed to predict severe complications after $72 \mathrm{~h}$ of treatment (dependent variable). The first model included clinical stability and levels of CRP on day 3 as the independent variable, the second model 
Figure 1 Median levels of $(A)$ C-reactive protein (CRP) and (B) procalcitonin (PCT) stratified by clinical stability with or without severe complications appearing after $72 \mathrm{~h}$.
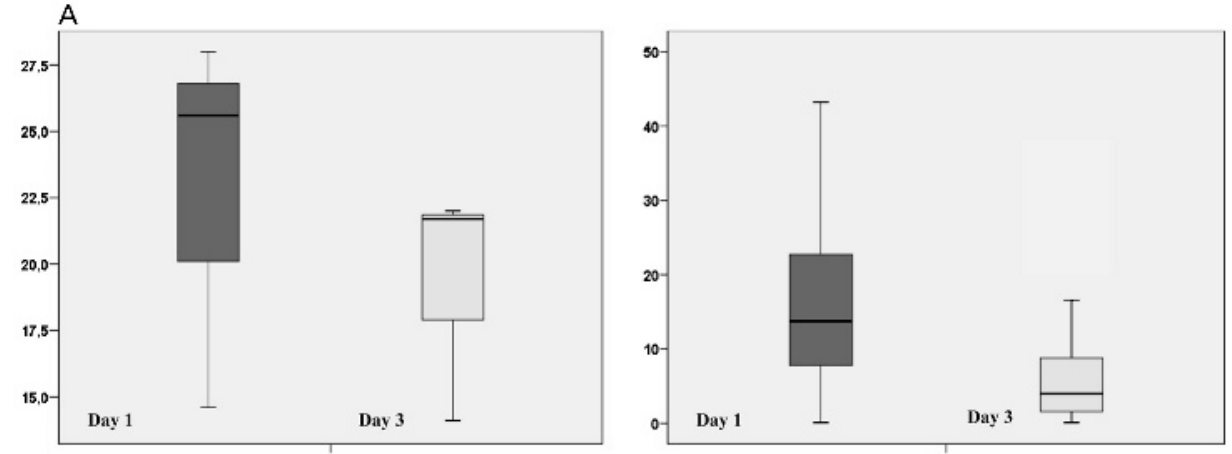

Clinical stability with complications after day 3

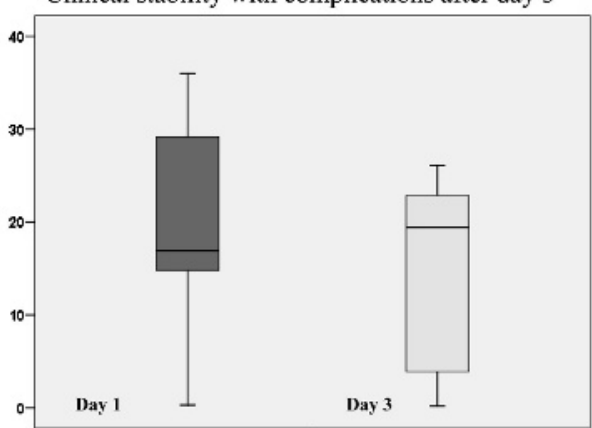

No clinical stability with complications after day 3

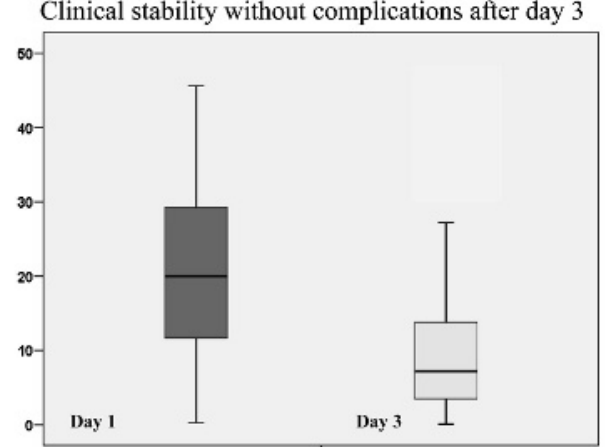

No clinical stability without complications after day 3

B

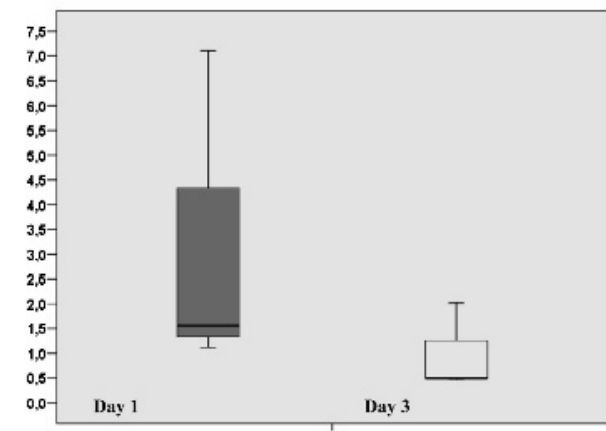

Clinical stability with complications after day 3

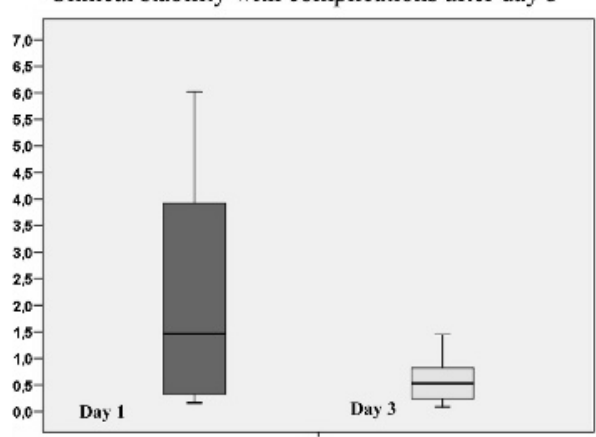

No clinical stability with complications after day 3 included clinical stability and levels of PCT, and the third model included clinical stability and levels of CRP and PCT. Clinical stability was a significant independent predictor for the absence of severe complications ( 0.78 (95\% CI 0.71 to 0.86$)$ ). CRP was also found to be a significant independent predictor $(0.86(95 \%$ CI 0.77 to 0.97$)$ ), but PCT was not independently associated (1.17 (95\% CI 0.78 to 1.76$)$ ).

The AUCs of the different logistic regression models with combinations of markers and clinical stability were calculated.
The AUC to predict the absence of severe complications after day 3 using clinical stability was 0.77 (95\% CI 0.64 to 0.90 ); when the CRP value was added, the area increased to 0.84 (95\% CI 0.75 to 0.92$), p=0.059$; and, when PCT was added, it was 0.77 (95\% CI 0.63 to 0.91$), p=0.45$.

\section{DISCUSSION}

The most important findings of our study are (1) that markers improve safety in predicting the absence of complications with 
Table 3 Predictive value of clinical stability criteria and biomarkers on day 3 for the absence of severe complications after $72 \mathrm{~h}$

\begin{tabular}{|c|c|c|c|c|c|c|c|}
\hline $\begin{array}{l}\text { Clinical criteria and } \\
\text { biomarkers }\end{array}$ & Sensitivity (\%) & Specificity (\%) & PPV (\%) & NPV (\%) & OR (95\% Cl) & LR+ & LR- \\
\hline Clinical stability & 58 & 83 & 99 & 9 & 6.8 (2.0 to 22.4 ) & 3.5 (1.5 to 9.9$)$ & $0.5(0.4$ to 0.7$)$ \\
\hline CRP < 3 mg/dl & 35 & 89 & 97 & 11 & $4.2(1.3$ to 13.7$)$ & 3.1 (1.2 to 9.1$)$ & 0.7 (0.6 to 0.9$)$ \\
\hline $\begin{array}{l}\text { Clinical stability + CRP } \\
<3 \mathrm{mg} / \mathrm{dl}\end{array}$ & 19 & 100 & 100 & 10 & $14.1(1.4$ to 138.8$)$ & $11.4(1.3$ to 110.0$)$ & $0.8(0.7$ to 0.9$)$ \\
\hline $\begin{array}{l}\text { Clinical stability + PCT } \\
<0.25 \mathrm{ng} / \mathrm{ml}\end{array}$ & 19 & 100 & 100 & 10 & 13.4 (1.4 to 131.7$)$ & $10.8(1.3$ to 104.0$)$ & $0.8(0.7$ to 0.9$)$ \\
\hline
\end{tabular}

$\mathrm{Cl}$, confidence interval; CRP, C-reactive protein; LR+, positive likelihood ratio; LR-, negative likelihood ratio; NPV, negative predictive value; $\mathrm{OR}$, odds ratio; PCT, procalcitonin; PPV, positive predictive value.

respect to the clinical criteria of stability; and (2) that a reduction in PCT levels to $<0.25 \mathrm{ng} / \mathrm{ml}$ and CRP levels to $<3 \mathrm{mg} / \mathrm{dl}$ together with clinical stability permits identification of patients with a high negative predictive value without subsequent severe complications.

Objective parameters such as these markers to identify clinical stability and to determine that the patient will not develop severe complications would be very useful to clinicians. This information is important to decide on subsequent followup, sequential treatment and possible discharge. It is well known that, if a patient is discharged when unstable, the likelihood of death is higher. ${ }^{16}{ }^{17}$ It is also known that the time between reaching clinical stability-mean of 3 days $^{211}{ }^{17}$-and discharge prolongs hospital stay, ${ }^{18}$ mainly because of a conservative or protective attitude to the possibility of complications arising after stability has been achieved and the lack of capacity to anticipate them. In fact, a modifiable process of care would be to reduce this time safely for the patient. Although previous studies have shown that one day of inhospital observation is not necessary after achieving stability and switching antibiotic treatment, ${ }^{19}$ some authors reported a non-significant trend towards lower 30-day mortality in a cohort receiving in-hospital observation. This finding, together with studies reporting that a reduction in length of stay was associated with a trend towards higher 30-day mortality, suggests that the clinical benefit of in-hospital observation cannot definitively be ruled out. ${ }^{20}$

Our results show that patients who achieved clinical stability within the first $72 \mathrm{~h}$ had significantly lower initial levels of PCT, CRP and cytokines (IL-6 and IL-10). These findings are plausible and support the idea that markers express the degree of systemic inflammation and reflect the response to resolution of the infection. Thus, high levels of markers and cytokines after $72 \mathrm{~h}$ of treatment are associated with therapeutic failure ${ }^{1}$ and death. ${ }^{21}$ Kellum et $a l^{21}$ have shown that the higher the initial levels of cytokines the worse the prognosis, and that the reduction in cytokine levels was faster during the first 3 days. ${ }^{21} 22$ Interestingly, persistence of inflammation after $72 \mathrm{~h}$ also has implications in medium- to long-term mortality. ${ }^{23}$ Yende et $a^{23}$ showed that high levels of IL-6 (mean $6.0 \mathrm{pg} / \mathrm{ml}$ ) at discharge and, to a lesser degree, of IL-10 (1.2 pg/ml) can increase the probability of death in the period between discharge and 3 months thereafter.

The capacity of CRP alone to predict severe complications at day 3 reached a diagnostic value similar to clinical criteria, with specificity and positive predictive value similar to the stability clinical criteria. We found that information on the reduction of systemic inflammation was complementary to clinical stability in ruling out subsequent complications. The study by Halm et $a l^{2}$ pointed out that severe complications are unlikely after clinical stability has been achieved, but progressive ageing of the population, an increase in the number of comorbidities and of multiple associated treatments (such as steroids) can interfere with the stability parameters. Our study confirms the high predictive value of the absence of severe complications after reaching stability $(3 / 135$ patients $(2.2 \%)$ with severe complications), but we found that these three patients still had high levels of CRP and PCT. In fact, the AUC for CRP to predict the absence of complications (AUC 0.77-0.84) increases the safety of clinical criteria for predicting complications. To calculate the threshold for the two markers, we selected that with a higher specificity and positive predictive value for the absence of severe complications. Although the addition of CRP or PCT to stability criteria only increased the specificity slightly, it was clinically highly relevant since it increased the safety for predicting the absence of severe complications.

It is also interesting to analyse the progress of patients with clinical instability on day 3 but with levels of biological markers below the established cut-off points. The probability of severe complications was also low (2.9\% if the CRP level was $<3 \mathrm{mg} / \mathrm{dl}$ and $4.9 \%$ if the PCT level was $<0.25 \mathrm{ng} / \mathrm{ml}$ ), and lower than if the levels of these markers remained high. Capelastegui et al ${ }^{17}$ reported that the clinical parameters of instability at discharge had a greater impact on mortality. Of the four parameters analysed (persistence of fever, systolic blood pressure $<90 \mathrm{~mm} \mathrm{Hg}$, respiratory rate $>24$ and oxygen saturation below $90 \%$ ), they found that persistence of fever had a closer relationship with mortality, which may be due to a higher systemic inflammation.

The importance of the reduction in the PCT levels has been used to calculate the duration of antibiotic treatment. ${ }^{6}$ These studies show that PCT levels $<0.25 \mathrm{ng} / \mathrm{ml}$ can be used to indicate suspension of treatment. Nevertheless, to our knowledge, there are no studies analysing the levels of markers together with stability information in CAP. The use of markers as an expression of inflammation is complementary to clinical parameters, alerting the clinician if they remain high-even if clinical stability is reached-and reducing the level of alert if they are reduced. The economic implications of early and safe discharge are enormous.

In conclusion, our results have shown that both clinical criteria of stability and reduction of biomarker levels after $72 \mathrm{~h}$ of treatment have a high negative predictive value for ruling out subsequent severe complications. The addition of the biological information provided by CRP and PCT levels to clinical criteria of stability improved the safety of that prediction. This 
information, if confirmed in other studies, would provide practical and useful information for safe early discharge in hospitalised patients with CAP.

Funding: Ciber de enfermedades respiratorias (CIBERES, una iniciativa del ISCIII), La Marató TV3 (040530), FIS PI04/1136 and Beca SEPAR (Sociedad Española de Neumología y Cirugía Torácica) 2003.

Competing interests: AT has served as consultant to and has received research grants from Brahms. The other authors have no competing interests.

Ethics approval: The study was approved by two ethics committees and the patients gave their signed informed consent.

Provenance and peer review: Not commissioned; externally peer reviewed.

\section{REFERENCES}

1. Menendez R, Cavalcanti M, Reyes $S$, et al. Markers of treatment failure in hospitalised community acquired pneumonia. Thorax 2008;63:447-52.

2. Halm EA, Fine MJ, Marrie TJ, et al. Time to clinical stability in patients hospitalized with community-acquired pneumonia: implications for practice guidelines. JAMA 1998;279:1452-7.

3. Mandell LA, Wunderink RG, Anzueto A, et al. IDSA/ATS consensus guidelines on the management of community-acquired pneumonia. Clin Infect Dis 2007:44(Suppl 2):S27-72.

4. Smith RP, Lipworth BJ, Cree IA, et al. C-reactive protein. A clinical marker in community-acquired pneumonia. Chest 1995;108:1288-91.

5. Hedlund $\mathbf{J}$, Hansson LO. Procalcitonin and C-reactive protein levels in communityacquired pneumonia: correlation with etiology and prognosis. Infection 2000;28:68-73.

6. Christ-Crain M, Stolz D, Bingisser R, et al. Procalcitonin guidance of antibiotic therapy in community-acquired pneumonia: a randomized trial. Am J Respir Crit Care Med 2006;174:84-93.

7. Christ-Crain M, Muller B. Biomarkers in respiratory tract infections: diagnostic guides to antibiotic prescription, prognostic markers and mediators. Eur Respir J 2007;30:556-73.

8. Chalmers JD, Singanayagam A, Hill AT. C-reactive protein is an independent predictor of severity in community-acquired pneumonia. Am J Med 2008:121:219-25.
9. Bruns AH, Oosterheert JJ, Hak E, et al. Usefulness of consecutive C-reactive protein measurements in follow-up of severe community-acquired pneumonia. Eur Respir $J$ 2008;32:726-32.

10. Montravers $\mathbf{P}$, Fagon JY, Chastre J, et al. Follow-up protected specimen brushes to assess treatment in nosocomial pneumonia. Am Rev Respir Dis 1993;147:38-44.

11. Menendez R, Torres A, Rodriguez de Castro F, et al. Reaching stability in community-acquired pneumonia: the effects of the severity of disease, treatment, and the characteristics of patients. Clin Infect Dis 2004;39:1783-90.

12. Fine $\mathbf{M J}$, Auble TE, Yealy DM, et al. A prediction rule to identify low-risk patients with community-acquired pneumonia. N Engl J Med 1997;336:243-50.

13. Lim WS, van der Eerden MM, Laing R, et al. Defining community acquired pneumonia severity on presentation to hospital: an international derivation and validation study. Thorax 2003;58:377-82.

14. Hanley JA, McNeil BJ. A method of comparing the areas under receiver operating characteristic curves derived from the same cases. Radiology 1983;148:839-43.

15. Hosmer D, Lemeshow S. Applied logistic regression. New York: John Wiley \& Sons, 1989

16. Halm EA, Fine MJ, Kapoor WN, et al. Instability on hospital discharge and the risk of adverse outcomes in patients with pneumonia. Arch Intern Med 2002;162:1278-84.

17. Capelastegui A, Espana PP, Bilbao A, et al. Pneumonia: criteria for patient instability on hospital discharge. Chest 2008;134:595-600.

18. Fishbane $\mathbf{S}$, Niederman MS, Daly C, et al. The impact of standardized order sets and intensive clinical case management on outcomes in community-acquired pneumonia. Arch Intern Med 2007;167:1664-9.

19. Nathan RV, Rhew DC, Murray C, et al. In-hospital observation after antibiotic switch in pneumonia: a national evaluation. Am J Med 2006;119:e511-7.

20. Metersky ML, Tate JP, Fine MJ, et al. Temporal trends in outcomes of older patients with pneumonia. Arch Intern Med 2000;160:3385-91.

21. Kellum JA, Kong L, Fink MP, et al. Understanding the inflammatory cytokine response in pneumonia and sepsis: results of the Genetic and Inflammatory Markers of Sepsis (GenIMS) Study. Arch Intern Med 2007;167:1655-63.

22. Boussekey N, Leroy 0 , Alfandari S, et al. Procalcitonin kinetics in the prognosis of severe community-acquired pneumonia. Intensive Care Med 2006:32:469-72.

23. Yende S, D'Angelo G, Kellum JA, et al. Inflammatory markers at hospital discharge predict subsequent mortality after pneumonia and sepsis. Am J Respir Crit Care Med 2008:177:1242-7.

\section{Keep up to date: sign up for our alerting services}

Find out automatically when an article is published on a specific topic or by a particular author. We can also alert you when an article is cited or if an eLetter or correction is published. You can also choose to be alerted when a new issue is published online [and when we post articles Online First]. Check out the New Content Alerts and Citation tracker from the Online tools section on the home page. 